\title{
Article \\ Non-Thermal Intervention of Lung Tumor by Core-Shell Magnetic Nanoparticles in a Magnetic Field
}

\author{
Naming Zhang ${ }^{1,2}{ }^{\mathbb{D}}$, Ziang Wang ${ }^{1}$, Shuya Ning ${ }^{3, *} \mathbb{D}$, Shuhong Wang ${ }^{1, *}$, Song Wang ${ }^{4}$ and Hao Qiu ${ }^{1} \mathbb{D}$ \\ 1 State Key Laboratory of Electrical Insulation and Power Equipment, School of Electrical Engineering, \\ Xi'an Jiaotong University, Xi'an 710049, China; namingzhang@xjtu.edu.cn (N.Z.); \\ s1mple@stu.xjtu.edu.cn (Z.W.); haoqiu@stu.xjtu.edu.cn (H.Q.) \\ 2 Department of Oncology, Johns Hopkins University School of Medicine, Baltimore, MD 21225, USA \\ 3 School of Electronic Information and Artificial Intelligence, Shaanxi University of Science and Technology, \\ Xi'an, 710021, China \\ 4 College of Water Resources and Architectural Engineering, Northwest A\&F University, \\ Xianyang 712100, China; sw@nwafu.edu.cn \\ * Correspondence: ningshuya@sust.edu.cn (S.N.); shwang@mail.xjtu.edu.cn (S.W.); \\ Tel.: +86-1327-928-9160 (S.N.); +86-1333-539-3137 (S.W.)
}

check for updates

Citation: Zhang, N.; Wang, Z.; Ning, S.; Wang, S.; Wang, S.; Qiu, H. Non-Thermal Intervention of Lung Tumor by Core-Shell Magnetic Nanoparticles in a Magnetic Field. Appl. Sci. 2021, 11, 2003. https:// doi.org/10.3390/app11052003

Academic Editors: Dimitrios Zografopoulos and Roberto Zivieri

Received: 22 January 2021

Accepted: 20 February 2021

Published: 24 February 2021

Publisher's Note: MDPI stays neutral with regard to jurisdictional claims in published maps and institutional affiliations.

Copyright: (c) 2021 by the authors. Licensee MDPI, Basel, Switzerland. This article is an open access article distributed under the terms and conditions of the Creative Commons Attribution (CC BY) license (https:/ / creativecommons.org/licenses/by/ $4.0 /)$.
Featured Application: The options for the treatment of K-Ras-driven lung tumors are currently limited. This study investigates the potential for non-thermal intervention against lung tumors using magnetic nanoparticles (MNPs) in a magnetic field. The MNPs for use in treating tumors were prepared by chemical methods. Simulations showed that the experimental platform can generate the desired magnetic field by avoiding any damaging rise in temperature and that the induced magnetic force can affect the cellular activities. Using MNPs in a magnetic field in this way can not only suppress the growth of tumor cells but also can strengthen the inhibitory effects of magnetic field stimulation on the lung tumors caused by the K-Ras mutations.

Abstract: K-Ras mutations result in normal cells dividing uncontrollably and becoming cancerous. The prognosis is currently poor for patients due to the lack of drugs that can effectively target these mutations. In this study, magnetic nanoparticles (MNPs) were prepared, characterized, and cooperated with a magnetic field to intervene in the growth of lung tumor cells. The rise in temperature of a stimulation coil was studied by numerical calculation. The non-thermal effects of MNPs under a magnetic force were analyzed. The cell experiments showed that the growth of A549 tumor cells slowed down. The result of a wound-healing assay also indicated that the migration of tumor cells was suppressed. Compared with magnetic stimulation without MNPs, MNPs enhanced the inhibitory effects of a magnetic field. This study suggests a new way to treat K-Ras driven lung tumors using non-thermal effects of MNPs without the side effects caused by thermal effects.

Keywords: tumor cells; nanoparticles; magnetic stimulation; numerical simulation

\section{Introduction}

Lung tumor is one of the most common malignant tumors, which is the leading cause of cancer-related death worldwide. K-Ras mutations result in normal cells dividing uncontrollably; however, few treatments can effectively target these mutations as both chemotherapy and radiation are harmful to normal lung tissues. Finding a new way to treat K-Ras lung tumors more effectively and with fewer side effects is, therefore, urgent and important.

An increasing amount of research is being conducted in the role of magnetic nanoparticles (MNPs) in the inhibition of cell proliferation [1-3] because their unique characteristics offer attractive applications in the treatment of tumors [4]. For example, MNPs whose surface has been biochemically modified can be concentrated in a given area, thereby 
achieving targeted aggregation. Ramesh shows the binding of epidermal growth factor receptor (EGFR) antibodies to MNPs and how they inhibit the growth of tumor cells through cytotoxic mechanisms [5]. In their study, MNPs act as carriers, delivering drugs to the tumor location. A. Espinosa et al. investigate how iron oxide MNPs can be used to kill tumor cells by inducing hyperthermia, generated using high frequency (up to $100 \mathrm{kHz}$ ) magnetic fields, at the tumor location [6]. The hyperthermia comes from the tissue-field interactions. It could affect normal tissues adjacent to tumor cells. Consequently, researchers have investigated the non-thermal properties of MNPs for potential interference with tumor cells. When an alternating magnetic field is applied to a nanoparticle, a mechanical force can be induced by the magnetic field. Previous studies show that MNPs are affected by this applied field [7]. In 2016, Chen reported the use of spin-vortex, disk-shaped permalloy magnetic particles in a low-frequency, rotating magnetic field for the in vitro and in vivo destruction of glioma cells [8]. In 2019, Lunov studied the magneto-mechanical modulation of iron oxide nanoparticles for remote actuation of apoptosis in liver cancer cells, which enabled remote activation of apoptosis in liver cancer cells [9]. Although magneto-actuated cell apoptosis was proposed in a number of studies, the phenomenon of the MNPs cooperated with the magnetic field on A549 tumor cells and internal mechanisms of this approach have not been fully discovered.

In this study, $\mathrm{Fe}_{3} \mathrm{O}_{4} @ \mathrm{SiO}_{2}$ core-shell nanoparticles were cooperated with a magnetic field to intervene in the proliferation and migration of a K-Ras-driven A549 lung tumor cell line. Section 2 presents the preparation and characterizations of MNPs. Section 3 shows the design and simulation of the experimental platform. Section 4 provides analysis and calculations of MNPs in a magnetic field. The force calculation shows the magnetic force induced by MNPs with a magnetic field. Section 5 provides details of cell experiments. The experiments and analysis show that MNPs cooperated with a magnetic field could suppress not only the proliferation of tumor cells but also cell migration. Section 6 concludes the paper. This study suggests a new way to suppress the proliferation of K-Ras-driven lung tumors using MNPs cooperated with a magnetic field.

\section{Preparation and Characterization of Magnetic Nanoparticles}

Nanoparticles have been widely applied in bioengineering applications, such as imaging, molecular detection, and drug delivery. They are usually based on ferrous ferric oxide to ensure responsiveness to the applied magnetic field; however, magnetic ferrous ferric oxides have many disadvantages, e.g., agglomeration, oxidation, and biotoxicity. To overcome these deficiencies, magnetic ferrous ferric oxide nanoparticles are often coated with silica, after which they possess higher biocompatibility. Figure 1a shows the process flow of MNPs in this research.

The $\mathrm{Fe}_{3} \mathrm{O}_{4} @ \mathrm{SiO}_{2}$ core-shell nanoparticles in this study were manufactured as follows. First, $100 \mathrm{~mL}$ of $1 \mathrm{~mol} / \mathrm{L} \mathrm{FeCl}_{3} \cdot 6 \mathrm{H}_{2} \mathrm{O}$ solution and $50 \mathrm{~mL}$ of $1 \mathrm{~mol} / \mathrm{L} \mathrm{FeCl}_{2} \cdot 4 \mathrm{H}_{2} \mathrm{O}$ solution were mixed in a $250 \mathrm{~mL}$ three-neck flask. Next, a water bath was heated to $60{ }^{\circ} \mathrm{C}$ and $0.5 \mathrm{~mol} / \mathrm{L}$ aqueous ammonia solution was added dropwise while stirring at $800 \mathrm{r} / \mathrm{min}$. As the color of the mixture gradually changed from orange-red to black, ammonia was added to maintain a $\mathrm{pH}$ of about 11 . The mixture was stirred for $30 \mathrm{~min}$, ultrasonically dispersed for $30 \mathrm{~min}$, and stirred again for $1 \mathrm{~h}$. Tetraethyl orthosilicate (TEOS) was added to the ethanol deionized water ammonia solution for $24 \mathrm{~h}$. Finally, the products were repeatedly washed with deionized water to ensure $\mathrm{pH}$ neutrality.

According to the procedure of the preparation, the MNPs were characterized by Transmission Electron Microscopy (TEM) and X-ray diffraction (XRD). Figure 1b shows the TEM of the prepared MNPs. The size diagram of the prepared MNPs has also been analyzed in Figure 1c. The mean diameter of the Fe3O4@SiO2 is $32.1 \mathrm{~nm}$ and the standard deviation is 5.1. The mean thickness of the $\mathrm{SiO}_{2}$ shell is $7 \mathrm{~nm}$. As can be seen from Figure 2a, the XRD patterns of the prepared $\mathrm{Fe}_{3} \mathrm{O}_{4} @ \mathrm{SiO}_{2}$ and the $\mathrm{F}_{\mathrm{e}} 3 \mathrm{O}_{4}$ samples were analyzed. To evaluate the magnetic properties, the magnetic hysteresis loop of the MNPs was measured by LakeShore 7404 VSM in Figure 2b, and the saturation magnetization is $14.2 \mathrm{emu} / \mathrm{g}$. 

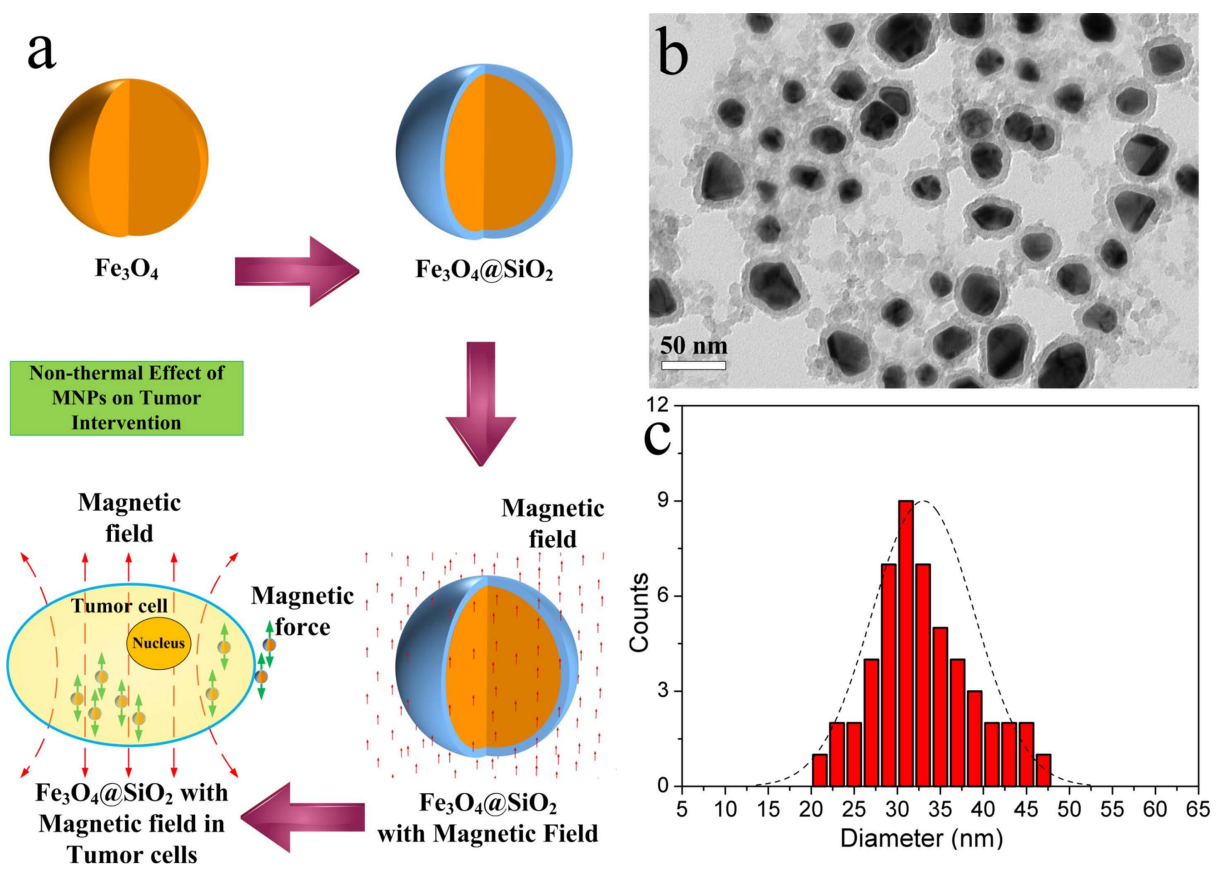

Figure 1. (a) Process flow of $\mathrm{Fe}_{3} \mathrm{O}_{4} @ \mathrm{SiO}_{2}$ magnetic nanoparticles (MNPs); (b) Transmission electron microscopy (TEM) image of prepared MNPs; (c) Size distribution histograms of prepared MNPs.
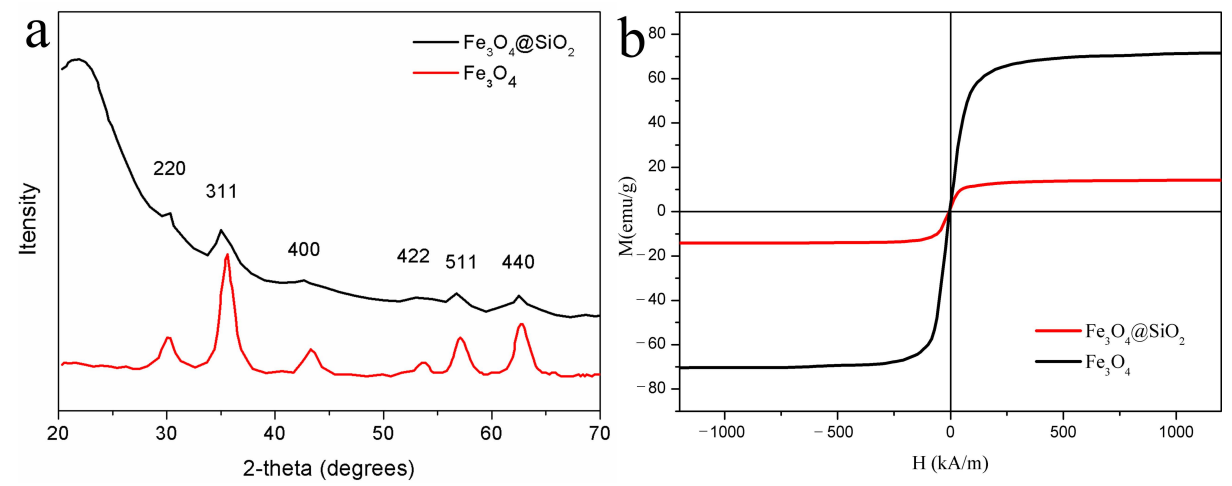

Figure 2. (a) X-ray diffraction (XRD) patterns of the MNPs. (b) Magnetic hysteresis loops of the MNPs.

\section{Design and Simulations of The Cell Experiment Platform}

The experiment platform comprised a signal generator, a stimulation coil, and a confocal microscope (LSM800, ZEISS, Germany). The frequency of the magnetic field could be adjusted by keyboard, and the intensity of the field could be changed by the potentiometer.

\subsection{Optimization of the Stimulation Coil Integrated with the Confocal Microscope}

To observe the growth of cells targeted by MNPs and the magnetic field, a $\mathrm{CO}_{2}$ incubator was integrated with a confocal microscope. To provide a clear optical path and ensure that images could be taken effectively, a planar spiral coil with a central hole to allow the transmission of light was designed and realized.

As shown in Figure 3a, there are 80 turns printed on a printed circuit board that has a small volume and is easily manufactured. The merits of the proposed coil are not only suitable for the confocal microscope but also have a satisfactory heat dissipation condition to avoid overheat. 


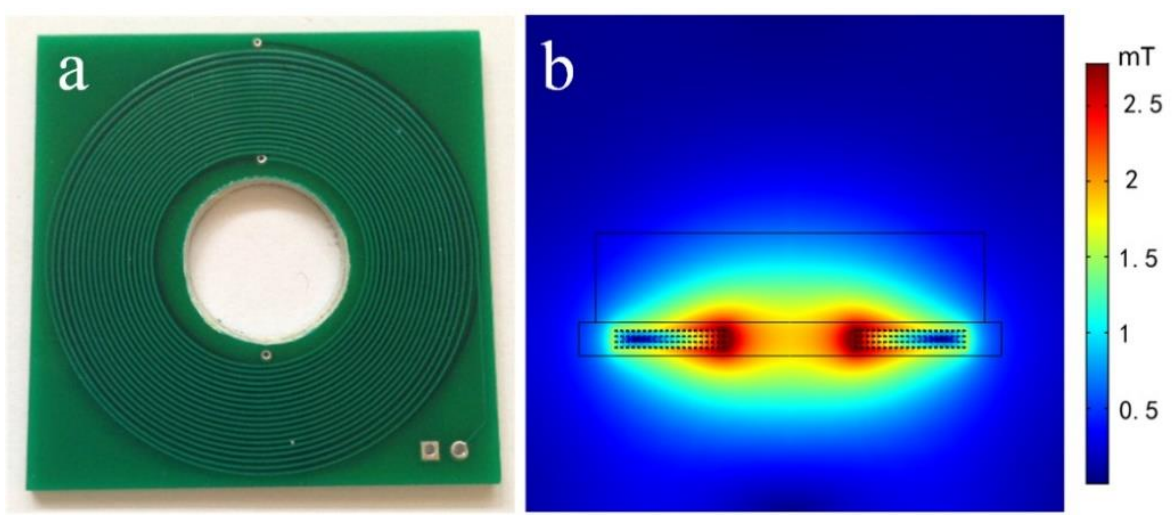

Figure 3. (a) The print circuit board (PCB) coil with a central hole. (b) The magnetic flux density of the stimulation coil.

\subsection{Simulation of the Magnetic Field}

According to Biot-Savart's law, the magnetic flux density of the coil can be calculated as

$$
\vec{B}=\frac{\mu_{0}}{4 \pi} \oint_{l} \frac{I d \vec{l} \times \vec{r}}{r^{3}}
$$

where $\mu_{0}$ is the space permeability, $I \vec{l} \vec{l}$ is the current element, $\vec{r}$ is the vector at a certain point, and $r$ is the distance between $I d \vec{l}$ and a certain point.

The $B_{z}$ of a certain point is calculated using

$$
B_{z}=\frac{\mu_{0} I}{4 \pi} \int_{0}^{2 \pi} \frac{R(R-y \cos \theta-x \cos \theta) d \theta}{\left[(x-R \cos \theta)^{2}+(y-R \sin \theta)^{2}+z^{2}\right]^{3 / 2}}
$$

where $R$ is the radius of the coil. The $x, y$, and $z$ are the coordinates at a certain point.

The total magnetic field intensity of the point above the center of the planar coil can be simplified as

$$
H_{N}(z)=\sum_{n=1}^{N} \frac{I R_{n}^{2}}{2\left(R_{n}^{2}+z^{2}\right)^{3 / 2}}
$$

where $N$ is the number of turns. According to Equation (3), the maximum magnetic flux density at the targeted area is $2.0 \mathrm{mT}$ by programming. As shown in Figure 3b, this result is close to the result of the FEM simulations. The magnetic flux density at the center of the culture dish was $1.8 \mathrm{mT}$.

\subsection{Calculation of the Rise in Temperature of the Stimulation Coil}

The air around the stimulation coil was heated by the current passing through it. At temperatures higher than $37.5^{\circ} \mathrm{C}$, cells can die through overheating. Therefore, it was necessary to analyze the temperature rise of the coil.

According to the heat equations [10], the temperature is calculated by

$$
\rho C_{p} \frac{\partial T}{\partial t}+\nabla \cdot(-k \nabla T)=Q .
$$

The heat source in Equation (4) is, thus, determined by

$$
Q=\frac{1}{2} \operatorname{Re}\left(J \cdot E^{*}\right) .
$$


As shown in Figure 4, the compared stimulation coil is the type of solenoid. The parameters of the two types of stimulation coil are shown in Table 1.

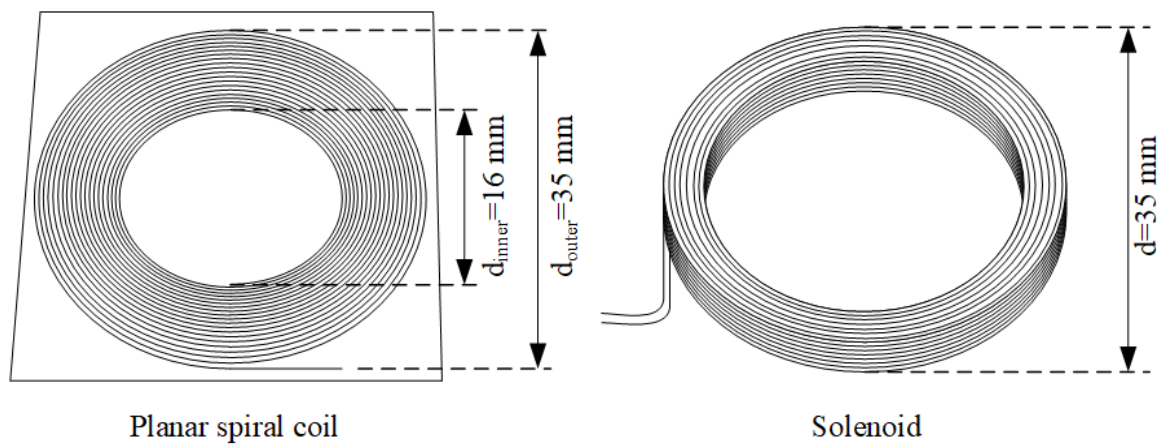

Figure 4. Structure diagram of two types of the stimulation coil.

Table 1. The structure of the detection coil array.

\begin{tabular}{cccc}
\hline Type & Diameter & Turns & Wire Diameter \\
\hline Planar spiral coil & $16 \sim 35$ & 80 & $0.25 \mathrm{~mm}$ \\
Solenoid & 35 & 80 & $0.25 \mathrm{~mm}$ \\
\hline
\end{tabular}

Figure 5 shows the rise in temperature of the planar coils compared with a planar solenoid coil. Based on the finite element method of calculation, the temperature at the location of the culture dish was lower than that of the solenoid coil.

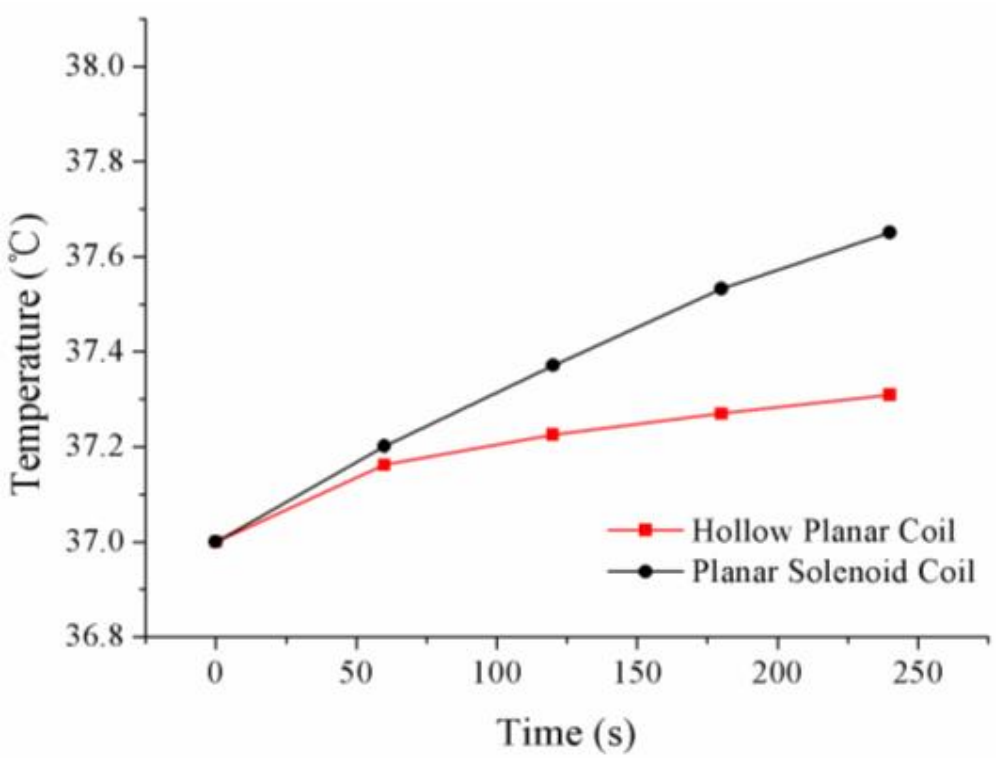

Figure 5. The temperature rises of the stimulation coil.

\section{Analysis of the Magnetic Nanoparticles}

When MNPs are placed in a magnetic field, they experience a magnetic force. The phenomenon allows the manipulation of MNPs using an applied magnetic field with appropriate parameters. In recent years, studies have explored the use of MNPs with a magnetic field in the "wireless" manipulation of cell adhesion and intercellular signaling [11,12]. By exploiting cell endocytosis, MNPs can enter cells and exert magnetic forces on the organelle [13]. Despite these advantages, the mechanism by which MNPs affect cell growth is still unclear. The non-thermal effects of MNPs guided by magnetic forces can be of key importance in the deployment of MNPs in a magnetic field against tumor 
cells. Therefore, analyzing and calculating the magnetic force and thermal field of MNPs is necessary.

\subsection{Force Analysis of MNPs in a Magnetic Field}

The magnetic field generated by a stimulation coil around MNPs can be considered a uniform field in calculations. Herein, a model of Helmholtz coil was established to generate a uniform magnetic field. The magnetic force can be calculated using the Maxwell stress tensor method. The Maxwell stress tensor is a second-rank tensor used in classical electromagnetism research to represent the interaction between electromagnetic forces and mechanical momentum [14].

Generally, the Maxwell stress tensor is an integral along with a closed area S around the target domain. As shown in Figure 6a, if the closed area $\mathrm{S}$ is located in a linear material, and the magnetic force can be obtained by Equation (6).

$$
F=\frac{1}{\mu_{0}} \oint_{S}\left(B(B n)-\frac{1}{2} B^{2} n\right) d S
$$

where $S$ is the surface element, and $n$ is a normal vector on closed area.
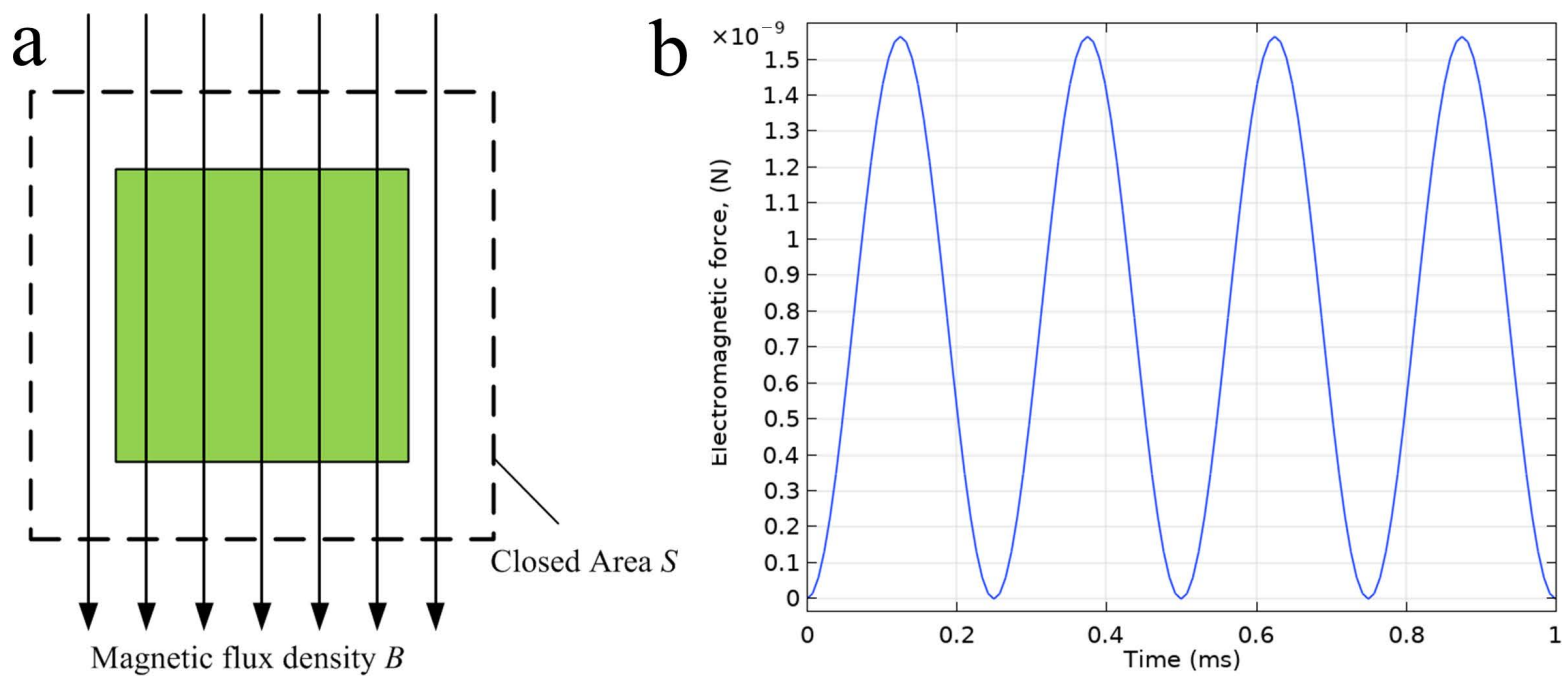

Figure 6. (a) Theory of the Maxwell stress tensor method. (b) Calculation of the magnetic force.

According to the previous research, taking into account the medium viscosity $(0.95 \mathrm{cP})$, the magnetic force calculated based on the Maxwell stress tensor method is shown in Figure $6 \mathrm{~b}$. During the stimulation of the magnetic field, the maximum magnetic force of MNPs induced by the applied magnetic field is around $1.5 \mathrm{nN}$. According to a previous study [15], the magnetic force can influence cellular activity. The MNPs cooperated with a magnetic field can be considered as a "nano-motor," and can be used to interfere with the growth of the cells.

\subsection{Thermal Analysis of MNPs in Magnetic Stimulations}

Cell proliferation is sensitive to temperature. Due to the side effects of MNPs in high-frequency magnetic fields, temperature rises should be avoided.

In this section, the rise in temperature of MNPs is calculated using the bioheat equation [16]:

$$
\rho c \frac{\partial H}{\partial t}=\nabla \cdot(k \nabla H)+c w\left(H-H_{a}\right),
$$

where $H$ is the actual temperature $\left({ }^{\circ} \mathrm{C}\right)$ and $H_{\mathrm{a}}$ is the temperature of the environment (assumed as a constant $37^{\circ} \mathrm{C}$ ), $k$ is the thermal conductivity of the culture medium, $c$ is the specific heat, and $w$ is the mass flow rate $\left(\mathrm{kg} / \mathrm{m}^{3} / \mathrm{s}\right)$. 
Based on the previous research, the frequency of the applied magnetic field for hyperthermia ranges from $100 \mathrm{kHz}$ to $450 \mathrm{kHz}$, and for magnetic-actuated ranges from $0.01 \mathrm{kHz}$ to $3 \mathrm{kHz}$. The concentration of MNPs inside the cells ranges from $5 \mathrm{pgFe} /$ cell to $25 \mathrm{pgFe} / \mathrm{cell}$ [17-19]. As shown in Figure 7, the thermal effect in high and low-frequency conditions and at different MNPs concentrations is studied by numerical calculation (with the same specification of MNPs). To determine the appropriate frequencies and concentration of MNPs, we have carried out various cell experiments with different frequencies and concentrations, and the response surface is established to reflect the relationship among concentrations of MNPs, frequency of the applied magnetic field, and thermal effect. The thermal effect of temperature rise was normalized for comparison. The response surface indicates that the higher concentrations of MNPs were in cells, the higher the thermal effect occurred. Moreover, the higher the frequency of the magnetic field applied, the higher the thermal effect was that occurred.

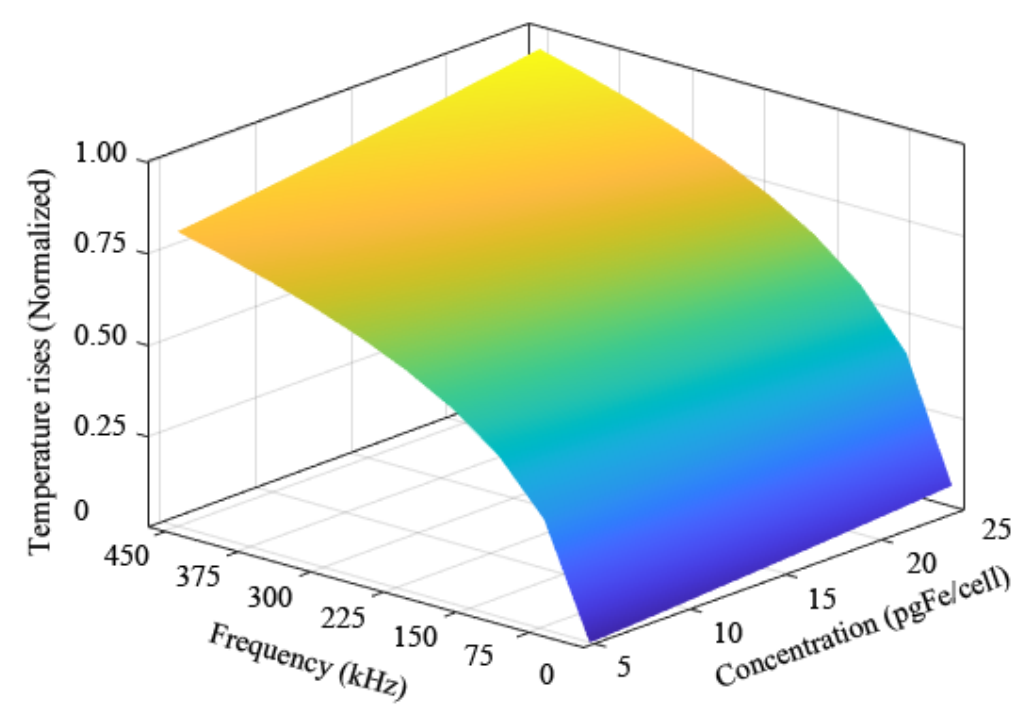

Figure 7. Response surface based on numerical calculation of magnetic field range from $0.01 \mathrm{kHz}$ to $450 \mathrm{kHz}$ and MNPs of different concentrations.

Thus, based on numerical calculation and cell experiments, the concentration of MNPs in the culture medium is specified as $5 \mu \mathrm{g} / \mathrm{mL}$ (corresponding to $16.51 \mathrm{pgFe} /$ cell) and the frequency of the applied magnetic field is $2 \mathrm{kHz}$.

\section{Cell Experiments}

\subsection{Preparation of A549 Lung Tumor Cells}

A549 tumor cells are adenocarcinomic human alveolar basal epithelial cells. These cells have played a key role in the development of lung tumor treatment. In this study, KRas mutated A549 tumor cells were obtained from the American Tissue Culture Collection. Considering the duration of the stimulation, the cells were carried on the passage with a ratio of 1:3. The fourth generation cells were used for the cell experiment.

According to the preparation of the MNPs, the particles were prepared and sterilized by ultraviolet (UV) irradiation, suspended in phosphate-buffered saline (PBS) and Roswell Park Memorial Institute (RPMI, Sigma Life Science, St. Louis, MO, USA) 1640 medium containing 10\% fetal bovine serum (FBS, Gibco by Life Technologies, Carlsbad, CA, USA). Before the cell experiments, the A549 cells were cultured and maintained in RPMI 1640 and supplemented with $10 \%$ fetal bovine serum (FBS). A549 cells were cultured in $75 \mathrm{~cm}^{2}$ flasks with $20 \mathrm{~mL}$ RPMI solutions. They were collected by digesting with trypsin EDTA from the flask. After digestion, the A549 tumor cells were transferred into a $35 \mathrm{~mm}$ culture dish with the MNPs-RPMI medium. 
To investigate the location of the MNPs, the A549 cells were labeled by RFP-GFPLC3 lentiviral transfection. As shown in Figure 8a, the nucleus is stained orange and the cytoplasm is stained green. According to the TEM image and light microscope image, the MNPs were endocytosed by A549 cells. In Figure 8b, the dark area shows that MNPs are endocytosed by tumor cells and aggregated inside the cells. As shown in Figure $8 \mathrm{c}$, the A549 cell is in apoptosis, stimulated by MNPs cooperated with a magnetic field.
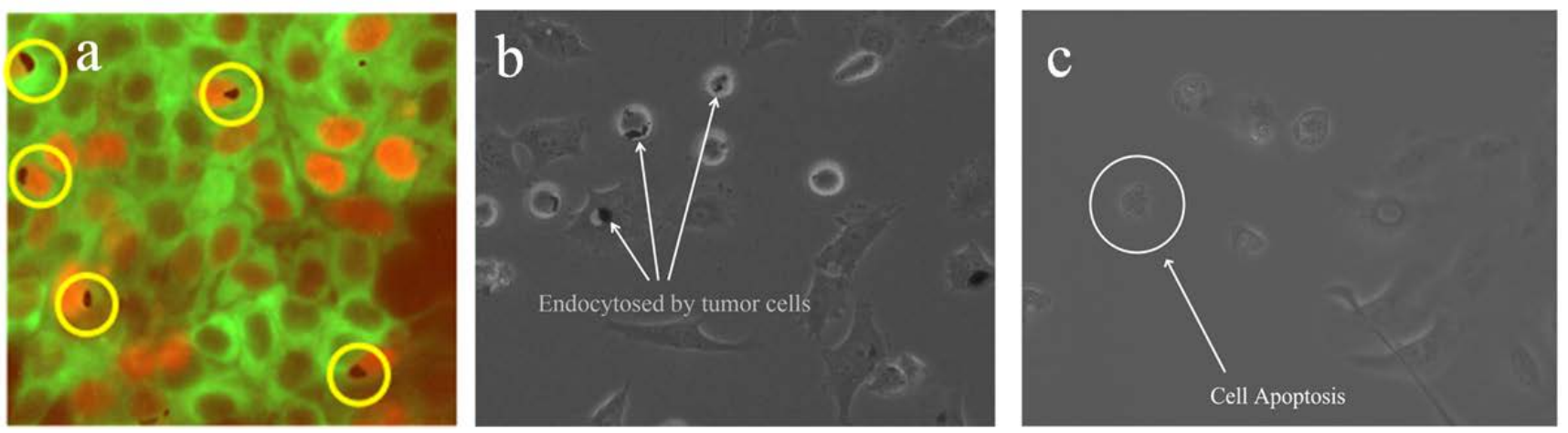

Figure 8. (a) The MNPs were endocytosed by cells and stained by lentivirus. (b) MNPs endocytosed by tumor cells. (c) Cell apoptosis driven by MNPs cooperated with a magnetic field.

\subsection{Cell Proliferation}

A549 cells were divided into four groups: Group A, Group B, Group C, and Group D. Cells in Group A were stimulated using a magnetic field, those in Group B were stimulated using a magnetic field cooperated with MNPs, those in Group C were the control group, and those in Group D were cultured with MNPs without the magnetic field. Our previous study showed that a magnetic field can suppress the growth of A549 cells [20,21]. To study the non-thermal effects of MNPs with a magnetic field, the cells were counted by an automated cell counter (TC10, BIO-RAD, Hercules, CA, USA) every $24 \mathrm{~h}$ and captured every $12 \mathrm{~h}$. As shown in Figure 9, after $72 \mathrm{~h}$, the ratio of cell proliferation in Group A has been suppressed by the magnetic field. Also, the ratio of cell proliferation in Group B is $14.7 \%$ lower than that in Group A. The group with only MNPs has no significant effect on cell proliferation. To ensure verifiable repeatability, the cell experiment was repeated three times.

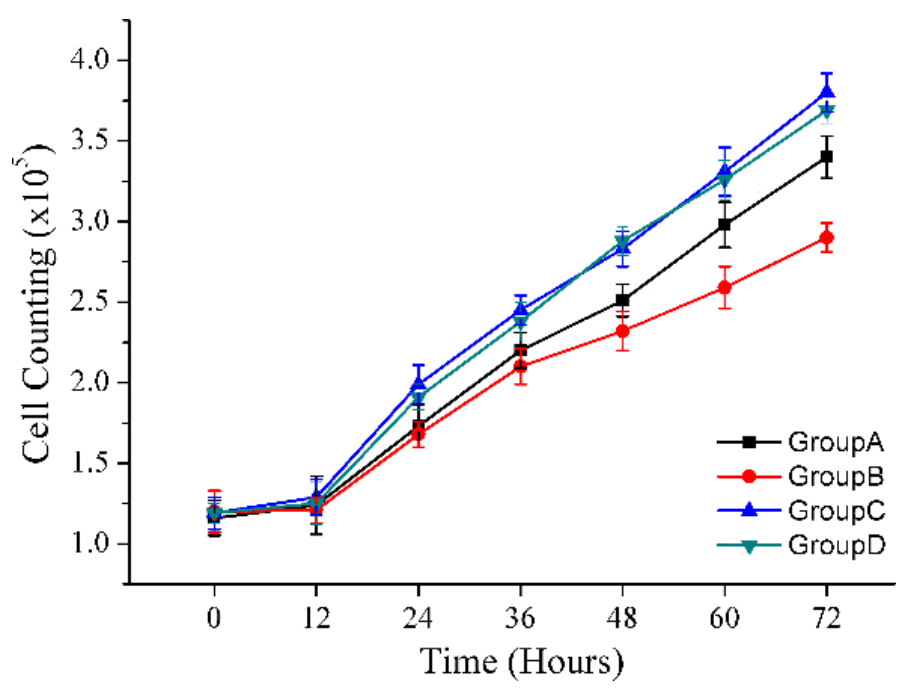

Figure 9. The cell counting of proliferation assay. 


\subsection{Scratch Wound-Healing Assay}

To discover the inhibitory effect on the migration of tumor cells, a scratch wound healing assay was conducted. The scratch wound healing assay has been widely adopted and modified to study the effects of a variety of experimental conditions. In a typical wound healing assay, it is specifically a 2D cell migration approach to semi-quantitatively measure cell migration of a sheet of cells. This scratch can be made through various approaches, such as mechanical, thermal, or chemical damage. The purpose of this scratch is to produce a cell-free area in hopes of inducing cells to migrate and close the gap [22].

As can be seen from Figure 10, by cell counting, the level of cell migration in Group B is $18.7 \%$ lower than that in Group A. This experimental result shows that MNPs cooperated with a magnetic field could suppress the migration of A549 tumor cells.

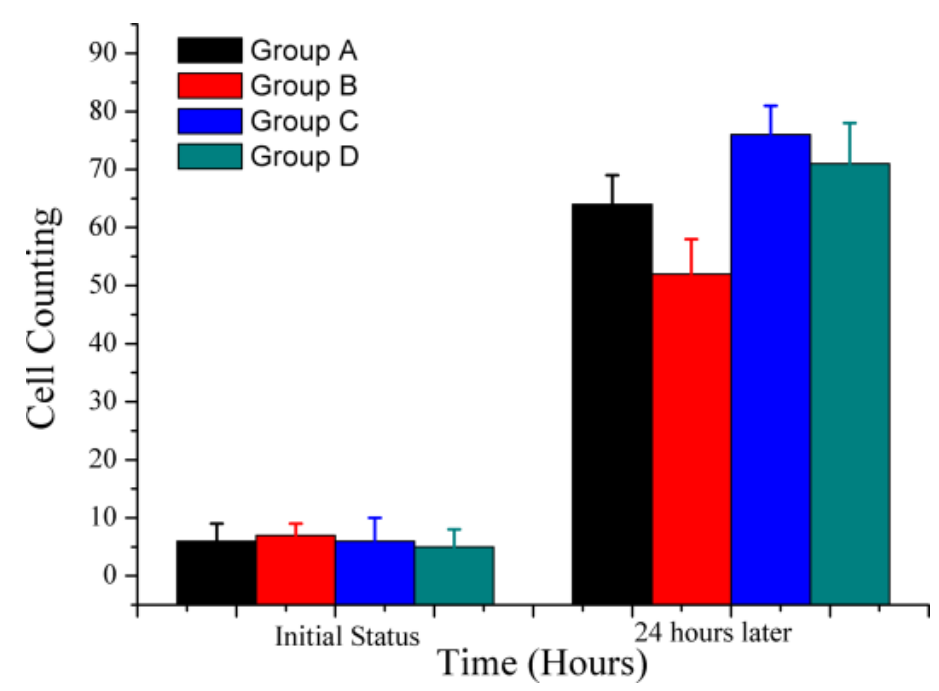

Figure 10. The cell counting of the wound-healing assay.

\section{Conclusions}

In this paper, MNPs for use in treating tumors were prepared and characterized. The magnetic force and thermal analysis of MNPs in a magnetic field were studied.

The simulations show that the experimental platform can generate the desired magnetic field while avoiding any notable temperature rises and that the induced magnetic force can affect cellular activities. The cell experiments illustrate that the rate of proliferation of A549 cells could be suppressed and the level of cell migration can be reduced. The relationship between the surface modification of MNPs and their non-thermal inhibitory effects on tumor cells will be investigated in future studies. This approach can not only suppress the growth of tumor cells but can also strengthen the inhibitory effects of magnetic field stimulation on lung tumors caused by K-Ras mutations.

Author Contributions: Conceptualization, N.Z., S.W. (Shuhong Wang); data curation, N.Z.; formal analysis, N.Z. and S.N.; funding acquisition, S.W. (Shuhong Wang) and N.Z.; investigation, Z.W. and N.Z.; methodology, Z.W. and N.Z.; project administration, S.W. (Shuhong Wang), N.Z. and S.N.; software, N.Z., S.W. (Song Wang), and Z.W.; supervision, S.W. (Shuhong Wang) and S.N.; validation, H.Q.; visualization, N.Z., and Z.W.; writing—original draft prep-aration, Z.W. and N.Z. All authors have read and agreed to the published version of the manuscript.

Funding: This research was funded in part by National Natural Science Foundation of China (51807159); China Postdoctoral Science Foundation (2017M620456, 2019M653635); Natural Science Basic Research Plan in Shaanxi Province of China (2019JQ-229, 2019JM-308); The Fundamental Research Funds for the Central Universities (xjj2018232). And the Scientific Research Funds for New Teacher of Xi'an Jiaotong University (DQ6K004); The Young Talent Fund of University Association for Science and Technology in Shaanxi (20200113); The Scientific Research Program of Shaanxi Provincial Education Department (20JG003). 
Institutional Review Board Statement: The study was conducted according to the guidelines of the Declaration of Helsinki, and approved by the Biomedical Research Ethics Committee of Xi'an Jiaotong University (protocol code 2018, No. 25, 9 March 2018).

Acknowledgments: Thanks are due to Bolan Lai for assistance with the data curation and validation. Deceased: This paper is dedicated to Chunyu Zhang, the principal investigator of this research.

Conflicts of Interest: The authors declare no conflict of interest.

\section{References}

1. Vegerhof, A.; Barnoy, E.A.; Motiei, M.; Malka, D.; Danan, Y.; Zalevsky, Z.; Popovtzer, R. Targeted magnetic nanoparticles for mechanical lysis of tumor cells by low-amplitude alternating magnetic field. Materials 2016, 9, 943. [CrossRef] [PubMed]

2. Shigeoka, D.; Yamazaki, T.; Ishikawa, T.; Miike, K.; Fujiwara, K.; Ide, T.; Oshima, A.; Hashimoto, T.; Aihara, D.; Kanda, K.; et al. Functionalization and Magnetic Relaxation of Ferrite Nanoparticles for Theranostics. IEEE Trans.Magn. 2018, 54, 6100707. [CrossRef]

3. Brizi, D.; Fontana, N.; Giovannetti, G.; Flori, A.; Menichetti, L.; Doumett, S.; Baldi, G.; Monorchio, A. A Novel Approach for Determining the Electromagnetic Properties of a Colloidal Fluid with Magnetic Nanoparticles for Hyperthermia Applications. IEEE J. Electromagn. RF Microw. Med. Biol. 2018, 2, 70. [CrossRef]

4. Li, W.; Liu, Y.; Qian, Z.; Yang, Y. Evaluation of tumor treatment of magnetic nanoparticles driven by extremely low frequency magnetic field. Sci. Rep. 2017, 7, 46287. [CrossRef]

5. Yokoyama, T.; Tam, J.; Kuroda, S.; Scott, A.W.; Aaron, J.; Larson, T.; Shanker, M.; Correa, A.M.; Kondo, S.; Roth, J.A.; et al. EGFR-Targeted Hybrid Plasmonic Magnetic Nanoparticles Synergistically Induce Autophagy and Apoptosis in Non-Small Cell Lung Cancer Cells. PLoS ONE 2011, 6, e25507. [CrossRef] [PubMed]

6. Espinosa, A.; Di, C.R.; Kolosnjaj-Tabi, J.; Flaud, P.; Pellegrino, T.; Wilhelm, C. Duality of Iron Oxide Nanoparticles in Cancer Therapy: Amplification of Heating Efficiency by Magnetic Hyperthermia and Photothermal Bimodal Treatment. ACS Nano 2016, 10, 2436. [CrossRef]

7. Chiriac, H.; Radu, E.; Tibu, M.; Stoian, G.; Ababei, G.; Labusca, L.; Herea, D.D.; Lupu, N. Fe-Cr-Nb-B ferromagnetic particles with shape anisotropy for cancer cell destruction by magneto-mechanical actuation. Sci. Rep. 2018, 8, 11538. [CrossRef]

8. Cheng, Y.; Muroski, M.E.; Petit Dorothée, C.M.C.; Mansell, R.; Vemulkar, T.; Morshed, R.A.; Han, Y.; Balyasnikova, I.V.; Horbinski, C.M.; Huang, X.; et al. Rotating magnetic field induced oscillation of magnetic particles for in vivo mechanical destruction of malignant glioma. J. Control. Release 2016, 223, 75. [CrossRef]

9. Lunov, Q.; Uzhytchak, M.; Smolkova, B.; Lunova, M.; Jirsa, M.; Dempsey, N.M.; Dias, A.L.; Bonfim, M.; Hof, M.; Jurkiewicz, P.; et al. Remote Actuation of Apoptosis in Liver Cancer Cells via Magneto-Mechanical Modulation of Iron Oxide Nanoparticles. Cancers 2019, 11, 1873. [CrossRef]

10. Pearce, J.A.; Cook, J.R.; Hoopes, P.J.; Giustini, A. FEM numerical model study of heating in magnetic nanoparticles. Energy-Based Treat. Tissue Assess. VI. 2011, 79, 79010B.

11. Dobson, J. Remote control of cellular behavior with magnetic nanoparticles. Nat. Nanotechnol. 2008, 3, 139. [CrossRef] [PubMed]

12. Wang, N.; Butler, J.P.; Ingber, D.E. Mechanotransduction across the cell surface and through the cytoskeleton. Science 1993, 3, 1124. [CrossRef] [PubMed]

13. Kim, D.H.; Rozhkova, E.A.; Ulasov, I.V.; Bader, S.D.; Rajh, T.; Lesniak, M.S.; Novosad, V. Biofunctionalized magnetic-vortex microdiscs for targeted cancer-cell destruction. Nat. Mater. 2010, 9, 165. [CrossRef]

14. Miller, F.P.; Vandome, A.F.; John, M. Maxwell Stress Tensor; Alphascript Publishing: Saarbrücken, Germany, 2010.

15. Tay, C.Y.; Cai, P.; Setyawati, M.I.; Fang, W.; Tan, L.P.; Hong, C.H.L.; Chen, X.D.; Leong, D.T. Nanoparticles Strengthen Intracellular Tension and Retard Cellular Migration. Nano Lett. 2014, 14, 83. [CrossRef]

16. Weinbaum, S.; Jiji, L.M. A new simplified bio-heat equation for the effect of blood flow on local average tissue temperature. J. Biomech. Eng. 1992, 114, 539. [CrossRef]

17. Atkinson, W.J.; Brezovich, I.A.; Chakraborty, D.P. Usable frequencies in hyperthermia with thermal seeds. IEEE Trans. Biomed. Eng. 1984, 1, 70. [CrossRef] [PubMed]

18. Contreras, M.F.; Sougrat, R.; Zaher, A.; Ravasi, T.; Kosel, J. Non-chemotoxic induction of cancer cell death using magnetic nanowires. Int. J. Nanomed. 2015, 10, 2141. [CrossRef] [PubMed]

19. Candeo, A.; Dughiero, F. Numerical FEM models for the planning of magnetic induction hyperthermia treatments with nanoparticles. IEEE Trans. Magn. 2009, 45, 1658. [CrossRef]

20. Zhang, N.M.; Wang, S.H.; Wang, S.; Zhang, C.Y. Theoretical Analysis and Design of a Variable Frequency Magnetic Field Stimulation System for Tumor Suppression. IEEE Trans. Appl. Supercond. 2016, 26, 1. [CrossRef]

21. Zhang, N.M.; Ning, S.Y.; Wang, S.H.; Zhang, C.Y.; Ren, Z.X.; Wang, S.; Hao, P.L. Study on the Effects of Magnetic Stimulation on K-Ras-Driven Lung Cancer in Mice. IEEE Trans. Magn. 2018, 54, 5001004. [CrossRef]

22. Jonkman, J.E.N.; Cathcart, J.A.; Xu, F.; Bartolini, M.E.; Amon, J.E.; Stevens, K.M.; Colarusso, P. An introduction to the wound healing assay using livecell microscopy. Cell Adhes. Migr. 2014, 8, 440. [CrossRef] [PubMed] 